\title{
Nanotechnology Enters the Renal Cancer Drug Delivery Arena: A Review
}

\author{
Madhuri Sharon ${ }^{1 *}$ and Chetna Sharon ${ }^{2}$ \\ ${ }^{1}$ Walchand Center for Research in Nanotechnology \&Bio nanotechnology, India. \\ ${ }^{2}$ Department of Internal Medicine, Hunter-Holmes McGuire, USA.
}

Received Date: August 15, 2018; Published Date: September 11, 2018

*Corresponding author: Madhuri Sharon, Walchand Center for Research in Nanotechnology \& Bio nanotechnology, WCAS, W.H. Marg, AshokChowk, Solapur,Maharashtra, India;Tel: 91 8655723028; Email: sharonmadhuri@gmail.com

\begin{abstract}
Unique pharmacokinetics, minimal renal filtration, controllable size and shape, high surface-to-volume ratios, easy functionalization to attach ligands, therapeutic agents and navigating molecules so that they can be internalizedare the properties of nanoparticles that have been used to deliver drugs to various cancer cells. Entry of nanotechnology for targeted drug delivery to renal cancer is in its infancy. This review apprehends the arsenal of different types of nanocarriers available that can be used for selective tumor targeting, and challenges in renal cancer treatment. Nanocarriers are much smaller than cancer cells therefore can be taken-up through leaky blood vessels and interact with targeted tumor-specific proteins both on the surface and inside cancer cells. Use of nanoparticles to thermally ablate kidney cancer is also touched upon. This review suggests that in future, owing to the efficacy of these novel agents, the therapy of renal cancer appears promising.

Keywords: Renal Cancer; Tumor; Nanotechnology; Drug deliver; Multi-Target Inhibitors.

Abbreviations: RCC: Renal Cell Carcinoma; TCC: Transitional Cell Carcinoma; SPIONs: Super-Paramagnetic Iron Nanoparticles; MITs: Multi-Target Inhibitors; SDI: Single-Drug Inhibitor; MDI: multi-drug inhibitors; VEGF: Vascular Endothelial Cell Growth Factor; EPR: Enhanced Permeability and Retention; BHD: Birt-Hogg-Dube; RES: Reticulo-Endothelial System; SLN: Solid Lipid Nanoparticles; CNTs: Carbon Nano-tubes; MWCNT: Multi walled CNT; SWCNT: Single Wall CNT; QD: Quantum Dot; NIR: Near Infra-Red Region; Dox: Doxorubicin; VNPs: Viral Nano Particles; CPMV: Cowpea Mosaic Virus; IFN $\alpha$ : Interferon alfa; IL-2: interleukin-2
\end{abstract}

\section{Introduction}

Renal (kidney) system is a filter to purify the blood. Renal cortical tumor could be malignant, indolent or benign [1].

\section{Types of Renal Cancer}

i. Renal Cell Carcinoma(RCC): That develops in the proximal renal tubules[2] having four major histological cell types i.e. Clear-cell, Papillary, Chromophobe and Collectingduct [3].

ii. Transitional Cell Carcinoma(TCC): Begins in the lining of the transitional cells of renal pelvis that line the ureters and bladder [4].

iii. Renal Sarcoma develops in the thin layer of blood vessel or connective tissue surrounding the kidney [5].

iv. Wilms Tumor (Nephroblastoma) forms in the kidney tissues that make urine [6].

v. Primary Renal Lymphoma is enlarged lymphadenopathy [7].

vi. Benign Kidney Tumor:Grows but do not metastasize.
Proteomics/metabolomics, mutational searches, gene expression profiling, and pathological/clinical studies have characterized different signalling pathways and many oncogenes and tumor suppressor genes associated with renal tumors, including those involved in tumorigenesis, progression and outcome of the cancer [8].

Major signalling pathways involved in RCC are:

(i) von Hippel-Lindau Gene Inactivation [9]

(ii) mTOR Pathway [10]

(iii) NF-кB Pathway [11]

(iv) NOx Pathway [12]

(v) Tyrosine Kinase Pathway [13]

(vi) HSP70 Pathway [14]

(vii) Mitogen-Activated Protein Kinase Pathway [15].

Conventional Therapeutic approaches to RCC (Surgery, Chemotherapy, Immunomodulatory therapy, Adjuvant therapy, 
Radiation therapy etc.) are guided by the stage or degree of tumor dissemination. Medical therapies are generally offered for locally advanced or metastatic renal-cell carcinoma in patients with the clear-cell type [3].As response rates are low, the need to identify new therapeutic agents is great[16].Other therapies as stem cell transplantation, targeting specific antigen e.g. G250 renal cancer antigen, which has been identified as CA9 [17] and combination of therapies targeting specific growth factors [18] is now being researched. RCC is highly resistant to chemotherapy. Generally, interleukin-2 or interferon alfa is used as first-line treatment of metastatic disease, but response to these cytokines is low.There are no alternative treatments for RCC that is resistant to cytokines; though some trials of treatment with an anti-angiogenic agent are being done [19].

\section{Why Nanotechnology}

Conventional drug delivery methods, harms both cancer and healthy cells, creating the need for targeted active and passive drug delivery.

The nanoparticles (1- $100 \mathrm{~nm}$ ) have altered physicochemical properties hence. exhibit altered interactions with cells and tissue. Nanoparticles can be used as drug delivery vehicle for targeted as well as controlled (timed release or single dose administration) drug release either by. Moreover, antibodies, nucleic acid, protein and peptides, needed for targeted drug delivery can also be carried by nanoparticles to the site of action. This avoids over dosing, side effects and harming the healthy cells [20]. Molecules can be attached either on the surface or encapsulated within. Encapsulation is of great advantage for suspension of insoluble drugs [21] and protection from degradation in the body prior to reaching its site [22]. Many therapeutic molecules used for kidney have rather poor pharmacokinetics [23], many small molecules are filtered and cleared from the kidney before they can have therapeutic effect or even cleared by the hepatic activity thus giving even less exposure to kidney.

Nano-vehicles has to be biocompatible, water soluble, $\mathrm{pH}$ specific, can protect premature drug delivery, has extended circulating life in the body, controlledinteraction of drug with cellular environment and easily functionalize and disposable after the drug delivery. The pharmacokinetic profile of nanoparticles has been found to be unique, including minimal renal filtration. Nanoparticles have high surface to volume ration, their surface can be modified by several functional groups so as to help in stabilizing and internalizing therapeutic agents. The drug distribution in tissues profile have exhibited increased differential uptake in the targeted cells than the healthy cells. Moreover, unique optical, electrical, magnetic and thermal properties of nanoparticles such as gold, silver, superparamagnetic iron nanoparticles (SPIONs) are being used for treating cancer through photothermal killing of tumor cells [24].
Renal Cancer being a multifactorial disease needs multitarget inhibitors (MITs) to take care of complications like development of resistance. Both single-drug inhibitor (SDI) and multi-drug inhibitors (MDI) are being used. At present there is no cure of metastatic RCC, therefore very limited use of nanotechnology is available. Potential of nanotechnology to develop early diagnostic devices such as sensing, imaging and remote actuation that can be combined with therapy will be of dual advantage.

\section{Nanoparticles Can Enter Cancer Cells Through Leaky Blood Vessels}

Cancerous tumors faces hypoxia hence needs more oxygen and for the growth of dormant avascular nodule needs more nutrients. Hypoxia condition activates angiogenesis i.e. new uncontrolled and excessive growth of blood vesselsthat gives rise to leaky blood vessels, through up-regulation of angiogenic cytokines and Vascular Endothelial Cell Growth Factor (VEGF). Angiopoietin such as integrins; are released by the tumor and host cells near the tumor. Hence, angiogenesis inhibitors drugs to block the angiogenesis in kidney cancers as anti VEGF such as Axitinib, Bevacizumab, Everolimus, Pazopanib, Sorafenib, Sunitinib, Camptothecinetc are in use. Tumors tissue has leaky blood vessels and poor lymphatic drainage. If drug is delivered using Nano-carrier it will extravasate into the tumor via leaky vessels by the enhanced permeability and retention (EPR). The dysfunctional lymphatic drainage in tumor facilitates nanocarriers to accumulate in tumor tissue and release drugs into the vicinity of the tumor cells. Whereas, free drug delivered by conventional methods often diffuse non-specifically into all cells. Nanoparticles-based drug delivery enhances permeability and retention (EPR) effect thus accumulating more nanoparticles in tumor tissue than in normal tissues by easy transfer of nanoparticles through the leaky blood vessels, which interacts with targeted tumor specific proteins, both on the surface and inside the cancer cell.

Major barriers in extravasations (leakage) of nanoparticles into the tumors are renal filtration, transport from plasma into tumor interstitial fluid among endothelial cells lining vessels and distribution within tumor interstitial fluid.

\section{Physiological and Biological Suitability of Nano constructs for Drug Delivery}

The characteristics for ideal drug delivery system are response to biologically relevant stimuli, stability, low toxicity, passive and active targeting. Micelle a Nano constructin which core is used for storing the drug and the outer core is functionalized to modify is physicochemical characteristics to facilitate the drug delivery [25].To prepare such nanoparticles polymers are also good option, which is achieved by heterogeneous polymerization of monomers [26]. For passive targeting characteristic features of tumors biology such as leaky 
blood vessels and poor lymphatic drainage, are exploited to allow the accumulation of nanocarriers in tumor by EPR effect.

\section{Targeted Drug Delivery to Renal Cancer}

Before considering targeted drug delivery to renal cancer cells it is important to have a cursory glance at the types of Renal Cancer Cells (RCC). There are as many as 20 different types of kidney cancer cells. RCC originates from the tubular structures of the kidney and is classified into four major histological cell types: Clear cell, papillary, chromophobe and collecting duct [3].

\section{Clear Cell}

Approximately $70 \%$ of kidney cancers are made up of clear or very pale cells ranging from slow growing (grade 1) to fast growing (grade 4). These cells are responsive to immunotherapy and targeted therapy $[27,28]$.

\section{Papillary}

It is the second most common subtype of renal cancer. 10\% renal cancers show presence of papillary cells (type 1 and type 2). This cancer forms finger-like projections (papillae) and are responsive to immunotherapy and targeted therapy [29]. No kidney cancer therapies have been developed to combat papillary renal cancer, though few are in development by the pharmaceutical companies [30].

\section{Sarcomatoid Features Carcinoma}

Disorganized clear cell, papillary and chromophobe, described by pathologists as "sarcomatoid" are indicative of very aggressive form of kidney cancer [31]. It accounts for approximately one in six cases of advanced kidney cancer.

\section{Medullary/Collecting duct}

An aggressive cancer closely related to TCC. It is common in black people and is highly associated with having the sickle cell trait $[32,33]$.

\section{Chromophobe}

An uncommon cancer that accounts for $\sim 5 \%$ of renal cancer that may form indolent tumors. These cancers cells are pale, like the clear cells, but are much larger [34,35].

\section{Oncocytoma}

A benign slow-growing tumor that rarely spread to different organs [36].

\section{Angiomyolipoma}

A benign tumor best treated with surgery, and rarely found in an aggressive form epithelioid, which could spread to nearby lymph nodes or organs. These tumors are made up of different types of connective tissues (blood vessels, smooth muscles, and fat) [37].They occur sporadically, and risk of life threatening hemorrhage is the main clinical concern.
Pathogenesis of renal cancer is complex and diverse and is influenced by multiple factors, some of which are related are smoking, obesity, work place exposure, genetic and hereditary risk factor, gene mutation (inherited or acquired) and presence von Hippel-Lindau disease, Hereditary papillary renal cell carcinoma, Hereditary leiomyoma-renal cell carcinoma, BirtHogg-Dube (BHD) syndrome, Familial renal cancer, Hereditary renal oncocytoma, Family history of kidney cancer and high blood pressure [38].

In conventional therapeutic method drug is absorbed through the membrane, often more than required and delivered to healthy tissues also. Whereas drug loaded nanoparticles along with navigating molecule delivers drug to specific tissue and avoids interaction with healthy tissue thus protecting them and are effective at reduced dose leading to minimized side effects.

There are two approaches for targeted drug delivery Passive Targeting and Active Targeting.

\section{i. Passive Targeting}

No navigating molecules are added to the drug loaded nanoparticles and they are directly delivered and accumulated in the tumor by the EPR effect. Passive targeting is done by extravasation of nanoparticles through increased permeability to tumor microenvironment, direct application and leaky tumor vasculature and EPR effect. Since EPR-effect is used as main criteria, therefore it is directly related to circulation time [39]. Liposome and polymer-protein conjugates are used for passive targeting. The surface of nanoparticles are coated with substances such as PEG to make it hydrophilic and the particles become hydrated, which makes this conjugate anti-phagocytic, thus the drug-loaded nanoparticles have prolonged stay in circulation. 10-100 nanometers are suitable and circulate for longer period [40].

\section{ii. Active Targeting}

Deciding a navigating molecule (antibody, folates/folic acid or vitamin) to be attached to the drug loaded nanoparticle; depends on the over expressed receptors on the membrane of cancer cells to which the drug will be targeted. Then it is easy to utilize cell-specific ligands that will allow for the nanoparticle to bind specifically to the cell that has the complimentary receptor and deliver the drug by endocytosis. Transferin is a good cell specific ligand to be conjugated with nanoparticles to target tumor cells having transferrin-receptor mediated endocytosis [41].

Active Targeting can be achieved by (i) Carbohydratedirected targeting, (ii) Receptor- and Antigen-directed targeting (iii) desired characteristics of Ligands and Antibodies (iv) Magneto-liposomes and (v) Peptide based drug targeting system [42]. A combination of both passive and active targeting using 
nanoparticle has advantage over conventional drug delivery [43].

\section{Overcoming Barriers Specific Biological Barriers: Penetrating Stroma}

The biological barriers in the human body are epithelia, endothelia, vascular endothelium; endosome, vascular endothelium, membranes of the cell and nucleus, activated monocytes and macrophages of the reticulo-endothelial system (RES), enzymatic degradation; sequestration by the phagocytes of the RES; adverse oncotic and interstitial pressures in the tumor; tumor interstitium andmolecular efflux pumps for the elimination of therapeutic agents. The sequential nature of barriers demands consideration for nano-vectors, surface modifications, therapeutic agents and penetration enhancers to be used for a multi-stage drug delivery strategy. The nanoparticles have to negotiate with all these barriers in order to attain a sufficient therapeutic index. In renal cancer there is a problem of restricting removal of drug and / or nanoparticles with filtration before they can exert their effect. In some situations, instead of delivering therapeutic agent to the cancer cells it is needed to be delivered to the other cell types within the tumor like macrophages or stromal tissue, which has been successfully done by polymeric nanoparticle to deliver siRNA to tumor-associated macrophages [44].

\section{Need of Multi-Target Inhibitors (MTIs)}

In multifactorial diseases complications that arise are development of resistance and toxicity due to non-specificity of drug delivery. Renal cancer being multi-factorial disease needs MTIs using either single-drug inhibitor (SDIs) or multi-drug inhibitors (MDI).

SDIs such as Kinase inhibitor simultaneously affect the multiple pathways, whereas MDIs inhibit multiple pathways because many combinatorial agents are used that act synergistically. Drugs for RCC that are in preclinical or clinical stage are Sorafenib, Sunitinib, Pazopanib and Cabozantinib. These drugs inhibit Vascular Endothelial Growth Factor Receptor; Platelet Derived Growth Factor Receptor and Mitogen Activated Protein pathway [45-47].

MTIs inhibit multiple signaling pathways thus has potential to cause systemic toxicity. Use of nanoparticles for targeted delivery of MTI ensures its accumulation in the tumor vasculature and reduces the systemic side effects.MDI uses synergistic drug combinations, which enhances the efficacy. Berenbaum[48] had suggested the use of combination agents as a solution for cancer therapy. Using nanotechnology, the ratio of different agents can be tailored to achieve optimal for different targets.Gowda etal. [49] have theoretically explained that if three inhibition agents are combined for MDI they cause $90 \%$ tumor inhibition, whereas separately they cause much less i.e. agent1causes $10 \%$, agent 2 causes $20 \%$ and agent 3 causes $10 \%$; in total only $40 \%$ inhibition.

\section{Suitability of Nanoparticles for Targeted Drug Delivery}

Use of nanotechnology for delivering drugs to renal cancer is still in its infancy. Kidneys filter blood through a structure known as the glomerular capillary wall. Nanoparticles $<10 \mathrm{~nm}$ diameter faces first pass renal filtration, hence, size of nanoparticles is very important.Dreher etal. [50] have shown that particles $>100$ $\mathrm{nm}$ diameter can accumulate in the tumor tissue, while being passively targeted, which is entirely dependent on diffusionmediated transport into the tumor. Stable nanoparticles that are in circulation for longer period, results in enhanced drug uptake by tumor and by avoiding reticuloendothelial system it minimizes the toxicity.

\section{Nanospheres}

(Figure 1a) can self-assemble, are biodegradable, their matrix is made of bovine serum albumin [51] or other amphiphilic copolymers [52], in which drug molecules are uniformly distributed. Nanospheres when used for delivering anti-angiostatin and endostatins (anti VEGF) [53,54] were found to be long circulating. Composition of the polymer matrix and its ability to imbibe fluids determines how rapidly the drug will be released [55]. These properties indicate that if tried Nanospheres may be suitable for delivering drugs to renal cancer tumor.

\section{Nanocapsules}

(Figure 1b) are composed of polymeric membranes and core of oil, which encompasses drugs [56] that can diffuse out under appropriate conditions, by responding to environmental, chemical, thermal or biological triggers [57-60].Nano capsules are colloidal and synthesized by interfacial deposition of preformed polymers [61] (PLA, PLGA, PCL and PEG) [6264]. It is suitable for the delivery of hydrophobic drugs. Lipid nanocapsules have been used for multi drug resistant cases in rat tumor [65]. Though not much work has been done on drug delivery to RCC using nanocapsules, but Hureaux etal.[66] have suggested a novel hybrid protein-lipid polymer nanocapsule of $180 \mathrm{~nm}$ as nontoxic drug for co-delivery of transcription factor p53 and lipophilic drug paclitaxel to induce HeLa cell apoptosis; this gives incentive to try using nanocapsules for delivering drugs to RCC.

\section{Micelles}

They are amphiphilic block of copolymers, that are biocompatible, biodegradable and self assembles in aqueous solution. They are aggregate of molecules in a colloidal solution, that can be Anionic (Sodium dodecylSulfate), Cationic (Cetylpyridinium bromide), Zwitterionic (lecithin) or Nonionic (Polyoxyethylene LaurylEther). There are reverse and bilayer micelle (Figure1c). Drugs entrapped in micelles have shown increased vascular permeability and impaired lymphatic drainage [67], causing EPR effect, suitable for passive targeting and can be used for controlled drug release [68]; thus, showing a potential for its use in RCC therapy. Suitability of micelle for 
MTI drug delivery [21]; for concurrent delivery of two or more MTI modalities [69]; as stimulus-responsive targeted [58]; easy tailoring to optimize delivery to solid tumors [70] and delivery of poorly soluble drugs [71] have been observed.

\section{Nano-Liposomes}

They are spherical, concentric bilayered vesicles having phospholipid membrane (Figure1d). The amphiphilic nature of liposomes, their ease of surface modification and a good biocompatibility make them an appealing solution for increasing the circulating half-life of proteins and peptides. The hydrophilic compounds remain encapsulated in the aqueous interior and hydrophobic compounds can escape encapsulation by diffusion through phospholipids membrane. Nano-liposomes can be designed to adhere to cellular membranes to transfer drugs following endocytosis. 100-200 nm nano-liposomes can rapidly enter tumor through vasculature. In nano-liposomes at a time many different molecules can be attached to the surface. PEG linked nano-liposomes are highly stable and have been used to deliver drugs to Brain [72] and colorectal cancer [73] but not for renal cancer. Since renal cancer has multiple signaling pathway, many nano-liposomal formulations containing therapeutic agents, antisense-oligodeoxynucleotides, siRNA, DNA or radioactive particles that can target multiple signaling pathway are being used for cancer treatment [74] and it can be of potential use for renal cancer also.

Use of nano-liposomes to deliver iron-oxide nanoparticles [30] for photothermal therapy of tumors and conjugation of nanoparticles of gold with liposomes for photothermal therapy and multi-model imaging [75] have also generated hopes for its use in renal cancer treatment.

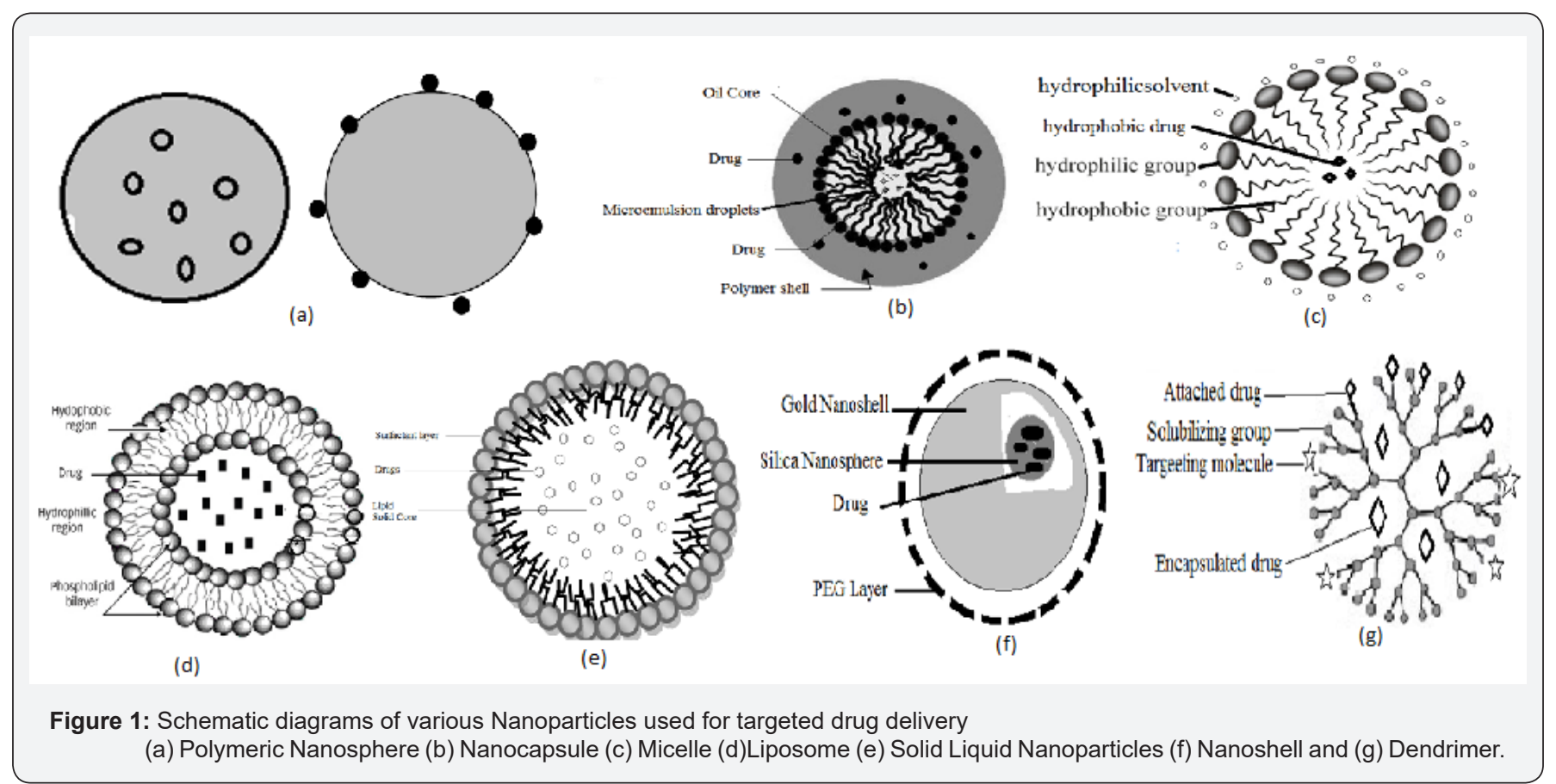

\section{Solid Lipid Nanoparticles (SLN)}

Theyare colloidal, spherical,drug carrier system [76] having solid lipid core matrix that can solubilize lipophilic molecules(Figure 1e). Lipids used are triglycerides (tristearin), diglycerides (glycerolbahenate), monoglycerides (glycerolmonostearate), fatty acids (stearic acid), steroids (cholesterol) and waxes (cetyl-palmitate). SLN are easy to biodegrade, less toxic than polymer or ceramic nanoparticles. Surface tailoring of SLN to load drugs is easy. SLNs can ferry bioactive selectively and specifically to the tumor sites with the interception of minimal side effects. They have controllable pharmacokinetic parameters and can be engineered with three types of hydrophobic core designs: a homogenous matrix, a drug-enriched shell or a drugenriched core.Zariwala [77] has shown use of SLN (lipid matrix composed of stearic acid) for oral iron delivery. Gaspar etal.
[78] have used SLN as transporter of therapeutic protein to lung epithelium. SLN can be an alternative to Liposomes and other polymeric nanoparticles. PEGylated SLNs has increased stability, bio-distribution and bio-availability of the conjugated drugs. Fundaro etal. [79] have demonstrated that PRG coated SLN carrying anticancer drug doxorubicin that reaches cancer cells in solid tumors more effectively than healthy tissues.

\section{Nanoshells}

They are spherical nanoparticle consisting of a dielectric core of silica covered by thin metallic shell (Figure 1f). Gold nanoparticles are preferred as outer layer of the shell because they are biocompatible and different types of molecules can be attached to them. Nanoshell can be injected safely. Phagocytes engulf the nanoshells through the cell membrane to form an internal phagosome. Nanoshell decorated with antigens that 
are expressed in cancer cell or tumor microenvironment; preferentially concentrate in the cancer cell because of their size and have enhanced EPR capacity. When light energy or radio frequency is externally applied to the cells where nanoshells are located, they create intense heat that selectively kills the tumor cells. The nanoshells can act as theranostic agent as they can be simultaneously used for detection and drug therapy.

\section{Dendrimers}

They are spheroid/globular nanoscale macromolecular compounds that form branches around the core (Figure 1g), offering multiple attachment sites for drug, antibody etc. The solubility and reactivity of dendrimer is influenced by the nature of surface groups. Dendrimers terminated in hydrophilic groups are soluble in polar solvents; whereas, dendrimers having hydrophobic end groups are soluble in non-polar solvents. Dendrimer solutions have significantly lower viscosity than linear polymers. Cationic (surface) charges are more toxic but it also depend on the specific groups involved, e.g. primary amines are relatively more toxic than secondary or tertiary amines. Anionic dendrimers, bearing a carboxylate surface are not cytotoxic over a broad concentration range.

There are three sections of dendrimers (Figure 1g), the outer multivalent surface containing potential reactive sites; layers below the surface have branches and few internal cavities and inner core. Based on their chemical structure the types of dendrimers are:

i. PAMAM Poly (amido-amine)suspended in methanol solutions.

ii. PAMAMOS are radially layered poly(amidoamineorganosilicon), which are inverted unimolecular micelles consisting of hydrophilic, nucleophilic PAMAM interiors and hydrophobic organosilicon exteriors.

iii. PPI-dendrimers "Poly (Propylene Imine) has primary amines as end groups andtertiary tris-propylene amines as interior.

iv. Multilingual dendrimers have surface composed of multiple copies of particular functional group.

v. Hybrid Dendrimers are Linear Polymers block or graft polymers of dendritic and linear polymers.

vi. Amphiphilic dendrimers has two segregated sites of chain end, one half is electron donating and the other half is electron withdrawing.

vii. Micellar dendrimers are unimolecular water soluble hyper branched polyphenylenes.

viii. Multiple Antigen Peptide dendrimers are dendron-like molecular construct based on a polylysine skeleton.

ix. Fréchet-Type is based on poly-benzyl ether hyper branched skeleton having carboxylic acid as surface groups, serving as a good anchoring point for further surface functionalization, and as polar surface groups to increase the solubility of this hydrophobic dendrimerin polar solvents or aqueous media.

x. Tecto Dendrimers are composed of a core dendrimer, surrounded by dendrimers of several steps to perform a function necessary for a s therapeutic nanodevices.

xi. Dendrimer based drug delivery system is already commercialized by Starpharma.

\section{Ceramic-Nanoparticles}

These are inorganic, heat-resistant, non-metallic solids made of both metallic and non-metallic compounds. Nano-ceramics are not brittle, they are dielectric, ferroelectric, piezoelectric, pyroelectric, ferromagnetic, magneto resistive, superconductive and electro-optical. They are fabricated from inorganic compounds of silica, titania etc. The silica based nano-ceramics are used for entrapping and releasing water insoluble drugs, it has potential of being used as drug carriers for photodynamic therapy [80] and used for bone repair. Not much near future application of Nanoceramics in cancer therapy is envisaged.

\section{Carbon Nano-tubes (CNTs)}

These are sheet of graphene rolled up into cylindrical form as Multi walled CNT (MWCNT) or Single Wall CNT (SWCNT). The diameter of SWCNT is usually $2 \mathrm{~nm}$ whereas diameter of MWCNT varies as per layers of multi-walls and ranges from 3 to $30 \mathrm{~nm}$. The size and surface properties of CNTs can be manipulated to circumvent rapid clearance by phagocytic cells, allowing both passive and active drug targeting. Controlled and sustained drug release from CNT can be obtained at the target site, improving the therapeutic efficacy and reducing side effects. Drug loading capacity of CNT is relatively high and may be achieved without chemical reactions by attaching drug directly to the dangling bonds present on the surface or inserting drug in CNT lumen (Figure 2a). CNT is chemically inert but use of CNT poses question regarding their biocompatibility and efficiency as a drug carrier. Functionalization of CNT has been tried to solve this problem byconjugating bioactive peptides, proteins, nucleic acids etc.[81]. Functionalized CNT displays low toxicity and are not immunogenic. Parihar etal.[82] have used functionalized CNT for the delivery of doxorubicin in vitro. CNT-based thermal tumor ablation therapies are being developed [83] by creating supra-physiologic temperature to kill malignant tissue [84] by denaturing the proteins and membrane lysis [85].

CNT has shown the potential for kidney cancer therapy.Joint effortsof Wake Forest University School of Medicine, the Wake Forest University Centre for Nanotechnology and Molecular Materials, Rice University and Virginia Tech, have shown that $80 \%$ of kidney tumors in mice was killed by injecting MWCNT into the tumors and heating them with a quick, 30-second zap of a laser. As compared to SWCNT, MWCNTs was found to be more effective at producing heat. 
Usability of CNT for renal cancer therapy can be judged by the fact that chemical functionalization of CNTs influences the blood clearance profile via renal or biliary pathway [86]. CNTs of up to 25-30 $\mathrm{nm}$ diameters and upto $500 \mathrm{~nm}$ length can exit the blood stream and be excreted in urine [87].Kostarelos etal. [88] have confirmed functionalization of CNT with hydrophilic groups aids in rapid renal clearance and low tissue retention. Shorter CNTs exhibit greater renal clearance than longer CNTs [89-91].

Wang etal. [22] have shown effective trans-membrane delivery of doxorubicin by endocytosis, using PEGylated oxidized mesoporous carbon nanospheres of $90 \mathrm{~nm}$ that was hydrophilic, stable, biocompatible, has high drug loading efficiency, could release drug under neutral $\mathrm{pH}$ and has prolonged circulation in the blood. The endocytosis, cytotoxicity, and anticancer effect in vitro and in vivo of the drug-loaded nanoparticles were also evaluated. It efficiently inhibited the growth of cancer cells both in vitro and in vivo and exhibited significant anti-metastasis effect in advanced stage of malignant cancer, improving the survival time of tumor-bearing mice. Thus, suggesting CNTs to be a promising anticancer drug delivery vehicle for renal cancer therapy.

\section{Quantum Dot (QD)}

Most of the QDs (CdSe, CdTe etc.) are highly cytotoxic. Capping of quantum dots with $\mathrm{ZnS}$ has been shown to augment stability and enhance luminescence with superior quantum yields at room temperature, however their suitability as drug delivery vehicle is still questionable.

Carbon quantum dots (CD) of 2-10nm [92] are being researched in medicine and theranostics due to its water solubility, small size, low toxicity, good biocompatibility, high photostability against photobleaching and blinking, broad excitation spectra, narrow and tunable emission spectra, synthesis from non-toxic precursors and above all having excellent Photoluminescent property in near infra-red region (NIR) which can be used for photothermal therapy also.A variety of carbon precursors such as graphene sheets, sucrose, amino acids, chitosan, carbon rich[93] and different surface passivation agents such as glutathione, PLGA, PEGhave been used for the synthesis of carbon dots [94]. CD has been used for attaching and delivering antibiotics[95].The anti-cancer drug doxorubicin (Dox) attachment capacity of Bovine Serum Albumin protected $\mathrm{CD}$, using folic acid as navigational molecule has also been explored [96]. Internalization of CDs specifically by HeLa cell was noted that followed First Order model release at pH 7.2. Dox. CD exhibited higher killing of HeLa cells and less cytotoxicity to normal cell than free Dox. CD has shown a synergistic conjugation with gold nano rod for anchoring DOX via covalent and noncovalent $\mathrm{pH}$ sensitive chemical bonds [97]. This complex had 94\% drug loading capacity under physiological conditions and showed a rapid release of Dox under NIR (808 $\mathrm{nm}$ ) radiation, proving that it can be used for thermo-chemotherapy.

\section{Metal and Inorganic Nanoparticles}

They are composed of inorganic compounds such as silica or alumina metals, metal oxides and metal sulfides creating a myriad of nanostructures with varying size, shape, and porosity. It is relatively easy to modify the surfaces of these particles with unique functionalities via variety of chemical transformations. Inorganic nanoparticles are relatively stable over broad ranges of temperature and $\mathrm{pH}$, yet their lack of biodegradation and slow dissolution raises safety questions, especially for long term administration. Metal nanoparticles have potential to produce monodispersity. Metallic nanoshells of $100-200 \mathrm{~nm}$ are used for imaging and therapy. Gold nanocages composed of gold nanorods, gold nanoparticles; iron oxide nanoparticles are examples of metallic nanoparticles and are used for diagnosis and thermo-ablative therapy. However, unlike polymeric nanostructures they are not biodegradable; this may cause accumulation in the body. Toxicity of nanoparticles can be reduced they can be excreted from the body by renal filtration by designing solubilizing organic coating which are biologically compatible with renal clearing. But the problem is that organic coatings often result in increase of the final hydrodynamic diameter.

\section{Proteins and Antibodies}

Glomerular proteins (LMWP) having MW<30,000 Da, such as lysozymes (MW $14 \mathrm{kDa}$ ) are being tried as they selectively accumulate in the kidneys and are biologically active in the circulatory system. LMWPs can be filtered at the glomerulus and reabsorbed in the renal tubules, they are non-immunogenic, biodegradable [98]. LMWP has many functional sites for linking drugs [99].

Chitosan is a natural copolymer of glucosamine and N-acetylglucosamine. Acetylated low MW chitosan has been used for kidney-targeted drug delivery because it is biocompatible and biodegradable $[20,100]$.Using PVD (Poly (Vinylpyrrolidone-coDimethyl); effect of MW and charge on its distribution in kidney [101] has been investigated; PVD of 6-8 kDa MW produced $80 \%$ renal targeting and good therapeutic effect. Peptides are also proposed as a targeting moiety for drug delivery chemotherapeutics. FITC-labelled G3-C12 peptide exhibited selective accumulation in mouse kidneys soon after injection.

Accumulation of actinomycin D-loaded isobutyl acrylate nanoparticles, an anti-inflammatory drug,in glomerular mesangial cells of rats have been reported [102]; where a nanoparticle-based therapeutics for targeting diseases that involve the kidney mesangium is constructed. It is Choi etal. [103] found that $75 \pm 25 \mathrm{~nm}$ diameter nanoparticles could be targeted to the kidney mesangium [18].

Attachment of Antibodies (Monoclonal Antibodies) to the surface of nanoparticles leads to targeting antigens present on the cancer cell membrane. So far unconjugated antibodies have been found to exert anti-tumor effect on many different types 
of cancer such as lymphomas, breast cancers, non-Hodgkin's lymphomas, colorectal cancers and chronic lymphocytic leukemia $[104,105]$. The specificity of antibodies does active targeting of a variety of tumor types and distinguishes between healthy and cancerous cells. However,there are certain limitations in use of antibody-based cancer therapy such as process is complex, rather expensive, non-uniform uptake in tumor [105], lack of tumor penetration due to increase in size of nanoparticle caused byhydrodynamic radius of antibodies $(\sim 20 \mathrm{~nm})$ and an uneven distribution of antigens $[105,106]$.

\section{Viral Nano Particles (VNPs)}

(Figure 2b) are emptied virus cells (empty of RNA) that can carry drugs to cancer cells. Usually plant viruses are chosen [107] because they are not pathogenic to human, biodegradable, biocompatible, monodispersion, are easy to produce in large quantities, can self-assemble around a nanoparticle in vitro, hold approximately 10 cubic nanometers of particles [108]. Outer capsids of virus composed of protein building blocks can be chemically and genetically engineered with targeting ligands and therapeutic molecule. Drugs can be easily attached to the surface of VNP, this helps viral cells to bond to cancer cells only. Often positively charged nanoparticle systems e.g. dendrimers and polymers, induces toxic effect by damaging membrane structure $[109,110]$, but positively charged VNP show enhanced tumor transport property and longer retention time in mammalian cells [111].VNP can be engineered to stimulate immune response to their cognate virus [112]. Moreover, VNPs have been shown to be well tolerated by mammalian cells in vitro.

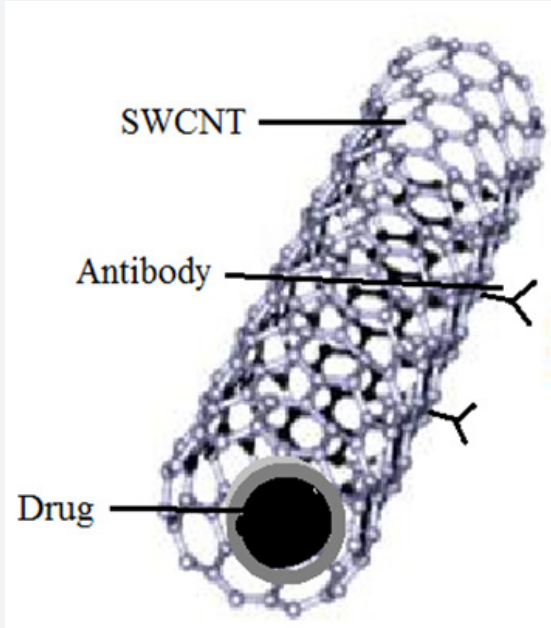

(A)

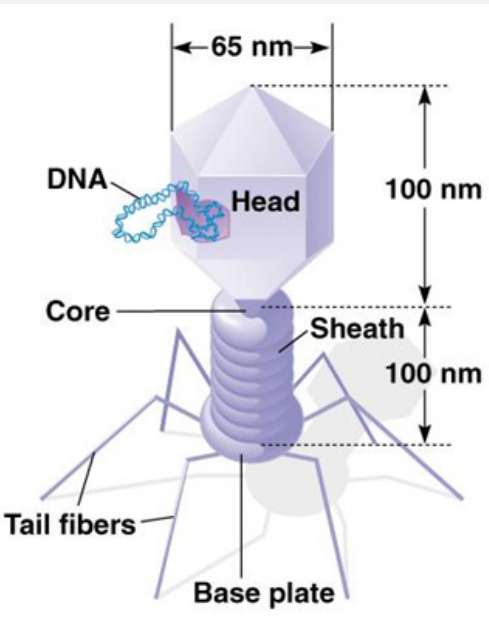

(B)

Figure 2: Schematic diagram of (A) CNT for drug delivery (B) A virus that can be used as cage for drug delivery (65 nm is capsids head).

Cowpea mosaic virus (CPMV) conjugated with iron oxide and using magnet from outside was tried to draw the nanoparticles to the cancer cells [113]. According to Franzen\& Lommel [108] VNP connected with iron oxide has higher chance of being toxic to human cells. Other disadvantages of using VNP are that viruses are composed of protein that may attack human immune system. When CPMV VNP coated with polymers to mask the protein, was orally administered to mice, no evidence of toxicity in mice was found [114]. Orally administered CPMV accumulated in convoluted tubules of the kidney and in draining lymph nodes [115], suggesting its possible use in renal cancer therapy.

Grasso etal.[113] have successfully employed Tomato bushy stunt virus from Nicotiana benthamiana for drug loading and their retention in inner cavity. Other viruses from insects and animals have also been used to engineer VNP. Canine parvovirus responded to transferrin release in human body which is over expressed in tumor cells [114]. Coating VNP with integrin facilitated this process. An imaging agent can also be attached to it to facilitate in locating the tumor [116-118].

\section{Nanotechnology for Targeted Drug Delivery to Renal Cancer}

Surgery is main cure for treatment of renal cancer in early stage. However, recurrence after surgery or developing metastasis remains a big concern. Since RCC is a highly vascular disease, is resistant to chemotherapy, there are trials to explore immunotherapy. Cytokines, Interferon alfa (IFN $\alpha$ ) and interleukin-2 (IL-2) treatment have been tried for metastatic RCC, but with very limited success $[119,120]$.Medicines such as Bisphosphonate andVEGF-targeted drug for the treatment of RCC metastasis are Cabozantinib [35], Sorafanib [33] are in use. Major considerations and strategies that are being employed to develop kidney-targeted drug delivery systems using nanotechnology, are to improve drug efficacy along with safety, assessment of types of nano-carriers, renal targeting conjugates, overcoming biological barriers and accessing the drugs to the cancer sites. Nanoparticles exhibit uniquepharmacokinetics and minimal renal filtration. Passive targeting administration of 
drugs can be difficult to access kidney tumor and it may involve injections or surgical procedures.

Kidney-targeted drug-delivery is focused on pharmacokinetic and pharmacodynamic studies in pathological conditions involving severe reductions in glomerular filtration. New nanocarriers are being constructed to target drugs to the glomerulus, mesangial cells and media fibroblasts. The cell surface receptor for folate is over expressed on the surface of kidney cancers/ malignancies. Folate-conjugated PEGylated cyanoacrylate nanoparticles have shown higher affinity for the folate receptor than free folate [121-123] so they are going to be one of the most sought after drug delivery system to renal cancer.Both PEGylated and Non-PEG, 85- 100 nm Nano-Liposomes loaded with Lurtotecan and Annamycin are also being tried for RCC [71].

Torti [124] has shown some hope in treating tumor cancer by injecting CNTs in mice kidney tumor and then heating them with a laser for only 30 seconds, which killed $80 \%$ of kidney tumor. Mice that received (i) no treatment for tumors, (ii) CNTs only or (iii) only laser treatment; died within 30 days. Whereas mice injected with MWCNTs followed by 30 -second laser treatment lived longer. Kidney tumors completely disappeared in $80 \%$ mice when highest quantity of MWCNTs was injected into the kidney tumors, these mice continued to live kidney tumor-free during nine months of study.

According to Torti"Multi-walled nanotubes (MWCNTs)are more effective at producing heat than other investigational nanomaterials," The speculations are that CNTs can be employed as drug delivery vehicle to deliver therapeutics to cellular level. However, prior to testing CNT in humans, studies need to be done to test the toxicity and safety if MWCNTs.Some considerations that should not be over looked are to minimize the accumulation of any non-biodegradable polymer or any other nanoparticle (used in drug delivery) having over the renal threshold size 31; and preventing the nanoparticles to cross the BBB.

Another issue that has been raised is can nanotechnology help in treating metastatic cancer that has cells of very small size, high multiplicity and are dispersed to diverse organ environments. For this the hope for very near future is only timely diagnosis. Delivering drugs to diverse organs, due to multifactorial causes of the cancer may take a lot of research to achieve.

\section{Conclusion}

Nanotherapy of renal cancer is still in its infancy. Occurrences of many different types of renal cancer, multifactorial nature of cancer and renal clearances are major hurdles. Suitability of different types of nanoparticles as drug carriers is discussed. CNTs have already been successfully used for hyperthermia treatment as well as drug delivery vehicle forrenal cancer.Some considerations that should not be over looked are to minimize the accumulation of any non-biodegradable polymer or any other nanoparticle (used in drug delivery) having over the renal threshold size 31 ; and preventing the nanoparticles to cross the BBB.

Another issue that has been raised is can nanotechnology help in treating metastatic cancer that has cells of very small size, high multiplicity and are dispersed to diverse organ environments. For this the hope for very near future is only timely diagnosis. Delivering drugs to diverse organs, due to multifactorial causes of the cancer may take a lot of research to achieve.

\section{References}

1. Jonasch E, Gao J, Rathmell WK (2014) Renal cell carcinoma. BMJ 349: g4797.

2. Turhal NJ (2002) Two Cases of Advanced Renal Cell Cancer with Prolonged Survival of 8 and 12 years. Jpn ClinOncol 32 (4): 152-153.

3. Herbert T, Cohen M, Francis J, McGovern MDN (2005) Renal-Cell Carcinoma, Engl J Med 353: 2477-2490.

4. Babaian RJ, Johnson DE, Llamas L, Ayala AG (1980) Metastases from transitional cell carcinoma of urinary bladder. Urology 16: 142-144

5. Wang X, Xu R, Yan L, Zhuang J, Wei B, Kang D, et al. (2011) Adult renal sarcoma: clinical features and ssurvival in a series of patients treated at a high-volume institution. Urology 77(4): 836-841.

6. Geller JI (2016) Current standards of care and future directions for "high risk" ped atric renal tumors. Anaplastic Wilms tumor and Rhabdoid tumor. Urol Oncol 34(1): 50- 56

7. Low G, Huang G, Fu W, Moloo Z, Girgis S (2016) Review of renal cell carcinoma and its common subtypes in radiology. World J Radiol 8(5): 484-500.

8. Gowrishankar B, Landes PC (2010) Signaling pathways in renal cell carcinoma. Caner Biol Ther 10(7): 658-664.

9. Kaelin WG Jr (2009) Treatment of kidney cancer: insights provided by the VHL tumor-suppressor protein. Cancer 115 (10 suppl): 2262- 2272

10. Borowska J, Schwartz RA, Kotulska K, Jozwiak S (2011) Tuberous sclerosis comples: tumors and tumorigenesis. Int. J. Dermatol 50(1): $13-20$

11. Zhang H, Sun Shao-Cong (2015) NF-KB in inflammation and renal diseases. Cell Biosci5: 63.

12. Fitzgerald JP, Nayak B, Shanmugasundaram K, Friedrichs W, Sudarshan S, etal.(2012) Nox4 Mediates Renal Cell Carcinoma Cell Invasion through Hypoxia-Induced Interleukin 6- and 8- Production. PLoS ONE 7(1): e30712.

13. Manash KP, Mukhopadhyay AK (2004)Tyrosine kinase-Role and significance in Cancer. Int J Med Sci. 1(2):101-115.

14. Sherman MY, Gabai VL (2015) Hsp70 in cancer: back to the future. Oncogene. 34(32): 4153-4161.

15. Dhillon AS (2007) MAP kinase signaling pathways in cancer.Oncogene 26: 3279-3290.

16. Motzer RJ (2003) Renal cell carcinoma: a priority malignancy for development and study of novel therapies. J Clin Oncol. 21: 1193-1194.

17. Steffens MG, Boerman OC, de Mulder PH, etal. (1999) Phase I radioimmunotherapy of metastatic renal cell carcinoma with 131Ilabeled chimeric monoclonal antibody G250. Clin Cancer Res 5: 3268s-3274s

18. Choueiri TK (2013) Clinical treatment decisions for advanced renal cell cancer. J Natl ComprCancNetw11(5 Suppl): 694-697. 
19. Motzer RJ, Hutson TE, Tomczak P, Michaelson D, Bukowski RM, et al. (2007) Sunitinib versus Interferon Alfa in Metastatic Renal-Cell Carcinoma. N Engl J Med356:115-124.

20. Wang S, J Luo, DA Lantrip, DJ Waters, CJ Mathias, et al. (1997) Design and synthesis of [111In] DTPA-folate for use as a tumor-targeted radiopharmaeutical. Bioconjug Chem 8 : 673-679

21. Singh R, Lillar JW (2009) Nanoparticle based targeted drug delivery. Exp Mol Pathol 86(3): 215-223.

22. Wang H, Li X, Ma Z, Wang D, Wang L, Zhan J, et al. (2016) Hydrophilic mesoporous carbon nanospheres with high drug-loading efficiency for doxorubicin delivery and cancer therapy 11: 1793-806.

23. Duncan R, Gaspar R (2011) Nanomedicine(s) under the microscope. Mol Pharm8: 2101-2141

24. El-Sayed IH, Huang XH, El Sayed MA (2006) Selective laser photothermal therapy of epithelial carcinoma using anti-EGFR antibody conjugated gold nanoparticles. Cancer Lett 239(1): 129-135.

25. Kataoka K, Harada A, Nagasaki Y (2001) Block copolymer micelle for drug delivery: design, characterization and biological significance. Adv. Drug Deliv Rev 47(1): 113-131.

26. Chacko RT, Ventura J, Zhuang J, Thayumanavan S (2012) Polymer nanogels: a versatile nanoscopic drug delivery platform. Adv. Drug Deliv Rev64: 836-851.

27. Chow WH, Dong LM, and Devesa SS (2010) Epidemiology and risk factors for kidney cancer. Nat Rev Urol 7(5):245-257.

28. Marcos F Dall'Oglio, Alberto A Antunes, Antonio C Pompeo, Alcides Mosconi, Katia RM Leite, et al. (2008) Prognostic relevance of the histological subtype of renal cell carcinoma. Int braz j urol 34(1) Rio de Janeiro Jan./Feb. 2008 Clinical Urology.

29. Leroy X, Zini L, Leteurtre E, Zerimech F, Porchet n, et al. (2002) Morphologic Subtyping of Papillary Renal Cell Carcinoma: Correlation with Prognosis and Differential Expression of MUC1 between the Two Subtypes. Mod Pathol 15(11): 1126-1130

30. Delahunt B, Eble JN (1997) Papillary renal cell carcinoma: a clinicopathologic and immunohistochemical study of 105 tumors. Mod Pathol 10: 537-544.

31. Shuch Brian, Gennady Bratslavsky, W Marston Linehan, Ramaprasad Srinivasan (2012) Sarcomatoid Renal Cell Carcinoma: A Comprehensive Review of the Biology and Current Treatment Strategies; Oncologist 17(1): 46-54.

32. Amin MB, Smith SC, Agaimy A, Argani P, Compérat EM, et al. (2014) Collecting duct carcinoma versus renal medullary carcinoma: an appeal for nosologic and biological clarity. Am J Surg Pathol 38(7): 871-874.

33. Andrew C Harbin, Brett A Styskel, Viren Patel, He Wang, Daniel D Eun (2015) Collecting Duct Renal Cell Carcinoma Found to Involve the Collecting System During Partial Nephrectomy: A Case Report. Journal of Kidney Cancer and VHL 2(3): 134-139.

34. Erlmeier F, Ivanyi P, Hartmann A, Autenrieth M, Wiedemann M, et al. (2017) c-Met in chromophobe renal cell carcinoma, Med Oncol 34(2):15.

35. Tsimafeyeu I (2017) Management of non-clear cell renal cell carcinoma: Current approaches; Urol Oncol 35(1): 5-13

36. Patel HD, Druskin SC, Rowe SP, Pierorazio PM, Gorin MA, et al. (2017) Surgical Histopathology for Suspected Oncocytoma on Renal Mass Biopsy: a Systematic Review and Meta-Analysis. BJU Int. 2017

37. Flum AS, Hamoui N, Said MA, Yang XJ, Casalino DD, et al. (2016) Update on the Diagnosis and Management of Renal Angiomyolipoma. J Urol 195(4 Pt 1): 834-46.
38. Koulari, Jung Sik Huh, Kyle O Rove, Luiza Crompton, Sweaty Koul, et al. (2011) Review Article Molecular aspects of renal cell carcinoma: Am J Cancer Res 1(2): 240-254.

39. Vlerken LEV, Vyas TK, Amiji MM (2007) Poly(Ethylene Glycol)Modified Nanocarriers for Tumor-Targeted and Intracellular Delivery. Pharm Res 24: 1405-1414.

40. Gullotti E, Yeo Y (2009) Extracellularly Activated Nanocarriers: A New Paradigm of Tumor Targeted Drug Delivery. Mol Pharm 6(4): 10411051.

41. Galvin P, Thompson D, Ryan KB, Mccarthy A, Moore AC, et al. (2011) Nanoparticle-Based Drug Delivery: Case Studies for Cancer and Cardiovascular Applications. Cell Mol Life Sci69(3): 389-404.

42. Hesieh WJ, Liang CJ, Chieh JJ, Wang SH, Lai IR, et al. (2012) In vivo tumor targeting and imaging with anti-vascular endothelial growth factor antibody-conjugated dextran-coated iron oxide nanoparticles. Int J Nanomedicine 7: 2833-2842

43. Mitra AK, Kwatra D, Vadlapudi AD (2015) Drug Delivery-Jones \& Bartlett Learning: Burlington, Massachusetts, United States.

44. Ortega RA,Barham WJ, Kuma B, Tikhomirov O, McFadden ID, et al. (2014) Biocompatible mannosylated endosomal-escape nanoparticles enhance selective delivery of short nucleotide sequences to tumor associated macrophages. Nanoscale 2: 500-510

45. Escudier B, Eisen T, Stafler WM, Szczylik C, Oudard S, et al. (2007) Sorafenib in advanced clear cell renal cell carcinoma. N Engl J Med 356(2): 125-134.

46. Vrdoljak E, Rini B, Schmidnger M, Omrcen T, Torday L, et al (2013) Bisphosphonate and vascular endothelial growth factor-targeted drugs in the treatment of patients with renal cell carcinoma metastatic to bone. Anticancer Drugs 24: 431-440.

47. Vaishampayan U (2013) Cabozantinib as a novel therapy for renal cell carcinoma. Curr Oncol Rep 15(2): 76-82.

48. Berenbaum MC (1985) The expected effect of a combination of agents: the general solution. J Theor Biol 114: 413-431.

49. Gowda R, Nathan RJ, Banerjee S, Robertson GP (2013)Use of Nanotechnology to Develop Multi-Drug Inhibitors for Cancer Therapy. Journal of Nanomedicine \& Nanotechnology 4: 184.

50. Top of Form

51. Bottom of Form

52. Dreher MR, Liu W, Michelich CR, Dewhirst MW, Yuan F, Chilkoti A (2006) Tumor vascular permeability, accumulation, and penetration of macromolecular drug carriers. J Natl Cancer Inst 98(5): 335-344.

53. Santhi K, Dhanaraj SA, Joseph V, Ponnusankar S, Suresh B (2002) A Study on the Preparation and Anti-Tumor Efficacy of Bovine Serum Albumin Nanospheres Containing 5-Fluorouracil. Drug Dev and Industrial Pharmacy 28(9): 1171-1179

54. Gref R, Minamitake Y, Peracchia MT, Trubetskoy V, Torchilin V, et al. (1994) Biodegradable long-circulating polymeric nanospheres. Science 263(5153): 1600-1603.

55. Chen QR, Zhang L, Gasper W, Mixson AJ (2001) Targeting tumor angiogenesis with gene therapy. Mol Genet Metab 74: 120-127.

56. Reynolds AR, Moein MS, HodiwalaDilke K (2003) Nanoparticle mediated gene delivery to tumor neovasculature. Trends Mol Med9: 2-4

57. Brigger I, Morizet J, Aubert GE, Chacun HEE, Terrier Lacombe ME, etal. (2002) Poly(ethylene glycol)-Coated Hexadecylcyanoacrylate Nanospheres Display a Combined Effect for Brain Tumor Targeting, J Pharmacol Exp Ther 303(3): 928-936. 


\section{Novel Approaches in Drug Designing \& Development}

58. Haley B, Frenkel E (2008) Nanoparticles for drug delivery in cancer treatment. Urol Oncol 26(1): 57-64.

59. Caldorera Moore M, Peppas NA (2009) Micro and nanotechnologies for intelligent and responsive biomaterial-based medical systems. Adv Drug Deliv Rev 61(15): 1391-1401.

60. Liechty WB, Peppas NA (2012) Expert opinion: Responsive polymer nanoparticles in cancer therapy. Eur J Pharm Biopharm 80: 241-246.

61. Peppas NA, Bures P, Leobandung W, Ichikawa H (2000) Hydrogels in pharmaceutical formulations. Eur J Pharm Biopharm. 50: 27-46.

62. Schoener CA, Hutson HN, Peppas NA (2013) Amphiphilic interpenetrating polymer networks for the oral delivery of chemotherapeutics. AIChE J 59: 1472-1478.

63. Fessi H, Puisieux F, Devissaguet JP, Ammoury N, Benita S (1989) Nanocapsule formation by interfacial polymer deposition following solvent displacement. Int J Pharm 55: R1-R4.

64. Ameller T, Marsaud V, Legrand P, Gref R, Barratt G, et al. (2003) PolyestrPoly(Ethylene Glycol) Nanoparticles Loaded with the Pure Antiestrogen RU 58668 Physiochemical and Opsonization Properties. Pharm Res 20(7): 1063-1070

65. Teixeira M, Alonso MJ, Pinto MMM, Barbos CM (2005) Development and characterization of PLGA nanoshere and nanocapsules containing xanthane and 3-methoxyxanthone. Eur J Pharm Biopharm 59(3): 491500

66. Prego C, Torres D, Fernandez Megia E, NovoaCarballal R, Quinoa E, et al. (2006) Chitosan-PEG nanocapsules as new carriers for oral peptide delivery. J Control Release 111: 299-308.

67. Garcion E , Lamprecht A, Heurtault B, Paillard A, Aubert Pouessel A, et al. (2006) A new generation of anticancer, drug loaded, colloidal vectors reverse multi drug resistance in glioma and reduces tumor progression in rats. Mol Cancer Ther 5: 1710-1722.

68. Hureaux J, Lagarce F, Gagnadoux F, Vecellio L, Clavreul A, et al. (2009) Lipid Nanocapsules: Ready-To-Use Nanovectors for the Aerosol Delivery of Paclitaxel. Eur J Pharm Biopharm 73 (2): 239-246.

69. Yokoyama M, Kwon GS, Okano T, Sakurai Y, Kataoka (1994) Development of micelle-forming polymeric drug with superior anticancer activity. ACS Symposium Series 545: 126-134.

70. Liu J, Xiao Y, Allen C (2004) Polymer-drug compatibility: A guide to the development of delivery systems for the anticancer agent, ellipticine. J Pharm Sci 93: 132-143.

71. Parhi P, Mohanty C, Sahoo K (2012) Nanotechnology based combinational drug delivery: an emerging approach for cancer therapy. Drug Discov Today 17: 1044-1052.

72. Muthu MS, Rajesh CV, Mishra A, Singh S (2009) Stimulus responsive targeted nanomicelles for effective cancer therapy. Nanomedicine (Lond) 4: 567-667.

73. Li W, Feng S, Guo Y (2012) Tailoring polymeric micelle to optimize delivery to solid tumors. Nanomedicine (Lond) 7:1235-252.

74. Torchilin VP (2005) Recent advances with liposomes as pharmaceutical carriers. Nat Rev Drug Discov 4: 145-160.

75. Zucker D, Barenholz Y (2010) Optimization of vincristine-topotecan combination-paving the way for improved chemotherapy regimens by nanoliposomes. J Controlled release 146: 326-333.

76. Aad G, Abbott B, Abdallah J, Abdelalim AA, Abdesselam A, et al. (2011) Search for dilepton resonances in pp collisions at vs_ $7 \mathrm{TeV}$ with the ATLAS detector. Phys Rev Lett 107: 272002.

77. Hu CM, Zhang L (2012) Nanoparticle based combination therapy towards overcoming drug resistance in cancer. BiochemPharmacol 83: 1104-1111.
78. Rengan AK, Jagtap M, De A, Bannerjee R, Srivastav R (2014) Multifunctional gold coated thermo-sensitive liposome for multimodal imaging and photothermal therapy of breast cancer cells. Nanoscale 6(2): 916-923.

79. Castelli F, Puglia C, Sarpierto MG, Rizza L, Bonina F (2005) Characterization of indomethacin-loaded lipid nanoparticles by differential scanning calorimetry. Int J Pharm 304: 231-238.

80. Zariwala, MG (2013) A novel approach to oral iron delivery using ferrous sulphate loaded solid lipid nanoparticles. Int J Pharm 456 (2): 400-407.

81. Gaspar DP (2015) Rifabutin-Loaded Solid Lipid Nanoparticles for Inhaled Antitubercular Therapy: Physicochemical and in Vitro Studies Int J Pharm 497(1-2): 199-209.

82. Fundaro A, Cavalla R, Bargoni A, Vighetto D, Zara GP, Gasco MR (2000) Nanostealth and stealth solid lipid nanoparticles (SLN) carrying doxorubicin: pharmacokinetics and tissue distribution after iv administration to rats. Pharma Res 42(4): 337-343.

83. Roy I, Ohulchanskyy TY, Pudavar HE, Bergey EJ, Oseroff AR, et al. (2003) Ceramic-based nanoparticles entrapping water-insoluble photosensitizing anticancer drugs: a novel drug-carrier system for photodynamic therapy. J Am Chem Soc 125(26): 7860-7865.

84. Bianco A, Kostarelos K, Prato M (2005) Applications of carbon nanotubes in drug delivery, CurrOpin Chem Biol 9: 674-679.

85. Parihar S, Sharon M, Sharon Madhuri (2006) Carbon Nano material Shows Drug Delivery Promise: Part1-Selection of Carbon Nano material \& Drug Loading. Synthesis \& Reactivity in Inorganic, Metal-Organic, \& NanoMetal Chemistry 36(1): 107-113.

86. Burke A, Ding XF, Singh R, Kraft RA, Levi-Polyachenko N, et al. (2009) Long-term survival following a single treatment of kidney tumors with multiwalled carbon nanotubes and near-infrared radiation. Proc Natl Acad Sci USA 106(31): 12897-12902.

87. Roti JLR (2008) Cellular responses to hyperthermia (40-46C): Cell killing and molecular events. Int J Hyperthermia 24: 3-15.

88. Falk MH, Issels RD (2001) Hyperthermia in oncology. Int J Hyperthermia 17(I): 1-18.

89. Liu Z, Davis C, Cai WB, He L, Chen XY, et al. (2008) Circulation and longterm fate of functionalized biocompatible single-walled carbon nanotubes in mice probed by Raman spectroscopy. PNAS 105(5): 1410-1415.

90. Ruggiero A, Villa CH, Bander E, Rey DA, Bergkvist M, et al. (2010) Paradoxical glomerular filtration of carbon nanotubes. PNAS 107(27): 12369-12374

91. Kostarelos K, Bianco A, Prato M (2009) Promises, facts and challenges for carbon nanotubes in imaging and therapeutics. Nat Nanotechnol 4: 627633.

92. Al Jamal KT, Nunes A, Methven L, Ali Boucetta H, Li SP, et al. (2012) Degree of Chemical Functionalization of Carbon Nanotubes Determines Tissue Distribution and Excretion Profile. Angew Chem Int Ed Engl 51(26): 6389-6393.

93. Deen WM, Lazzara MJ, Myers BD (2001) Structural determinants of glomerular permeability. Am J Physiol Renal Physiol 281(4): F579-F596.

94. Lacerda L, Herrero MA, Venner K, Bianco A, Prato M, et al. (2008) Carbonnanotube shape and individualization critical for renal excretion. Small 4(8): 1130-1132.

95. Sun YP, Wang X, Lu F, Cao L, Meziani MJ, et al. (2008) Doped carbon nanoparticles as a new platform for highly photoluminescent dots. J Phys Chem C Nanomater Interfaces 112(47): 18295-18298.

96. Thakur M, Mewada A, Pandey S, Bhori M, Singh K, et al. (2016) Milkderived multi-fluorescent graphene quantum dot-based cancer theranostic system. Mater Sci Eng C 67: 468-477. 
97. Baker SN, Baker GA (2010) Luminescent Carbon Nanodots: emergent nanolights. Angew. Chem Int Ed 49: 6726-6744.

98. Thakur M, Pandey S, Mewada A, Patil V, Khade M, et al. (2014) Antibiotic Conjugated Fluorescent Carbon Dots as a Theranostic Agent for Controlled Drug Release, Bioimaging, and Enhanced Antimicrobial Activity. Journal of Drug Delivery 2014: Article ID 282193: 9.

99. Mewada A, Pandey S, Thakur M, Jadhav D, Sharon Madhuri (2014) Swarming Carbon Dots for Folic acid Mediated Delivery of Doxorubicin and Biological Imaging. Journal of Materials Chemistry B 2: 698-705.

100. Pandey S, Mewada A, Thakur M, Shah R, Sharon Madhuri, et al. (2013) Biogenic gold nanoparticles as flotillas to fire Berberine hydrochloride using folic acid as molecular road map. Mater Sci Eng C Mater Biol App 33(7): 3716-3722.

101. Zhou P, Sun X, Zhang Z (2014) Kidney-targeted drug delivery systems, Acta Pharmaceutica Sinica B 4(1): 37-42.

102. Geng $Q$ S Sun X, Gong T, Zhang ZR (2012) Peptide-drug conjugate linked via a disulfide bond for kidney targeted drug delivery. Bioconjug Chem 23: $1200-1210$.

103. Su M, He Q Zhang ZR, Hu B, Liu SW (2003) Kidney-targeting characteristics of $\mathrm{N}$-acetyl-l-glutamic prednisolone prodrug. Acta Pharm Sin. 38: 627-630.

104. Yamamoto Y, Tsutsumi Y, Yoshioka Y, Kamada H, Sato Kamada K, et al. (2004) Poly(vinylpyrrolidone-co-dimethylmaleicacid) as a novel renal targeting carrier. J Control Release 95: 229-237.

105. Manil L, Davin JC, Duchenne C, Kubiak C, Foidart J, et al. (1994) Uptake of nanoparticles by rat glomerular mesangial cells in vivo and in vitro. Pharm Res 11: 1160-1165.

106. Choi CH, Zuckerman JE, Webster P, Davis ME (2011) Targeting kidney mesangium by nanoparticles of defined size. Proc Natl Acad Sci USA 108(16): 6656-6661.

107. Mehren MV, Adams GP, Weiner LM (2003) Monoclonal Antibody Therapy for Cancer. Annu Rev Med 54: 343-369.

108. Weiner LM, Adams GP(2000) New approaches to antibody therapy. Oncogene 19: 6144-6151.

109. Gu FX, Karnik R, Wang AZ, Alexis F, Levy Nissenbaum E, et al. (2007) Targeted nanoparticles for cancer therapy. Nano Today 2:14-21.

110. Saunders K, Sanisbury F, Lomonossoff G (2009) Efficient generation of cowpea mosaic virus empty virus-like particles by the proteolytic processing of precursors in insect cells and plants. Virology 393 (2): 329-337.

111. Franzen S, Lommel S (2009) Targeting cancer with 'smart bombs': equipping plant virus nanoparticles for a 'seek and destroy' mission. Nanomedicine 4(5): 575-588.

112. Hong S, Bielinska AU, Mecke A, Keszler B, Beals JL, Shi X etal. (2004) Interaction of poly(amidoamine) dendrimers with supported lipid bilayers and cells: hole formation and the relation to transport. Bioconjug Chem 15: 774-782.

113. Garnett MC, Kallinteri $P(2006)$ Nanomedicine and nanotoxicology: some physiological principles. Occu Med 56: 307-311.

114. Wen Am, Rambhia PH, French RH, Steinmetz NF (2013) Design rules for nanoengineering: from physical virology to the applications of virus based materials in medicine. J Biol Phys 39: 1-25.

115. Grasso S, Lico C, Imperatori F, Santi L (2013) A plant derived multifunctional tool for nanobiotechnology based on Tomato bushy stunt virus. Transgenic Res 22(3): 519-535.

116. Singh P, Destito G, Schneemann A, Manchester M (2006) Canine parvovirus-like particles, a novel nanomaterial for tumor targeting. Journal of Nanobiotechnology 4: 2 .

117. Esfandiari N, Arzanani MK, Soleimani M, Kohi Habibi M, Svendsen WE (2016) A new application of plant virus nanoparticles as drug delivery in breast cancer. Tumor Biol 37(1): 1229-1236.

118. Aljabali AAA, Barclay JE, Butt JN, Lomonossoff GP, Evans DJ (2010a) Redox-active ferrocene-modified Cowpea mosaic virus nanoparticles. Dalton Transactions 32: 7569-7574.

119. Aljabali AAA, Sainsbury F, Lomonossoff G, Evans DJ (2010b) Cowpea mosaic virus unmodified empty virus-like particles can be loaded with metal and metal oxide. Small 6: 818-821.

120. Aljabali AAA, Barclay JE, Lomonossoff GP, Evans DJ (2010c) Virus templated metallic nanoparticles. Nanoscale 12: 2596-2600.

121. McDermott DF, Atkins MB (2004) Application of IL-2 and other cytokines in renal cancer. Expert Opin Biol Ther 4(4): 455-468.

122. Hutson TE, Quinn DI (2005) Cytokine therapy: a standard of care for metastatic renal cell carcinoma? Clin Genitourin Cancer 4(3): 181-186.

123. Stella B, Arpicco S, Peracchia MT, Cattel L, Couvreur P, et al. (2000) Design of folic acid-conjugated nanoparticles for drug targeting.J Pharm Sci 89(11): 1452-464.

124. Mewada A, Pandey S, Thakur M, Jadhav D, Sharon Madhuri (2014) Swarming Carbon Dots for Folic acid Mediated Delivery of Doxorubicin and Biological Imaging. Journal of Material Chemistry B 2: 698-705.

125. Pandey S, Thakur M, Mewada A, Anjarlekar D, Sharon Madhuri, et al. (2013) Carbon Dots Functionalized Gold Nanorod Mediated Delivery of Doxorubicin: Tri-functional nano-worms for Drug delivery, Photothermal therapy and Bioimaging" Journal of Materials Chemistry 1: 4972-4982.

126. Torti SV (2011) Targeted Nanoparticles for Kidney Cancer Therapy principal investigator: Ph.d. Contracting organization: Wake Forest University Winston-Salem, NC 27157-0001 Report Date: October 2011 TYPE OF REPORT: Annual PREPARED FOR: U.S. Army Medical Research and Materiel Command Fort Detrick, Maryland 21702-5012, USA. 
This work is licensed under Creative Commons Attribution 4.0 License

DOI: 10.19080/NAPDD.2018.04.555631
Your next submission with Juniper Publishers will reach you the below assets

- Quality Editorial service

- Swift Peer Review

- Reprints availability

- E-prints Service

- Manuscript Podcast for convenient understanding

- Global attainment for your research

- Manuscript accessibility in different formats

( Pdf, E-pub, Full Text, Audio)

- Unceasing customer service

Track the below URL for one-step submission https://juniperpublishers.com/online-submission.php 